\title{
Espécies novas e notas sobre Dianthidiini (Hymenoptera, Megachilidae) do Peru ${ }^{1}$
}

\author{
Danúncia Urban ${ }^{2,3}$
}

\begin{abstract}
${ }^{1}$ Contribuição $\mathrm{n}^{\circ} 1463$ do Departamento de Zoologia, Universidade Federal do Paraná. ${ }^{2}$ Departamento de Zoologia, Universidade Federal do Paraná. Caixa Postal 19020, 81531-980 Curitiba-PR, Brasil. ${ }^{3}$ Bolsista do CNPq.
\end{abstract}

\begin{abstract}
New species and notes on Dianthidiini (Hymenoptera, Megachilidae) from Peru. Duckeanthidium tarapotoense sp. nov. and Grafanthidium yurimaguasano sp. nov. from Tarapoto, Yurimaguas; Anthodioctes sanmartinensis sp. nov. and Anthodioctes shilcayensis sp. nov. from Tarapoto, Boca Toma, are described and illustrated. The male of Anthodioctes indescriptus (Dalla Torre, 1890) is described for the first time and new records of Bothranthidium lauroi Moure, 1947, are given.
\end{abstract}

KeYwords. Dianthidiini; Neotropical; new records; new species; taxonomy.

Resumo. São descritas quatro espécies novas de Dianthidiini do Peru: Duckeanthidium tarapotoense sp. nov. e Grafanthidium yurimaguasano sp. nov. de Tarapoto, Yurimaguas; Anthodioctes sanmartinensis sp. nov. e Anthodioctes shilcayensis sp. nov. de Tarapoto, Boca Toma. O macho de Anthodioctes indescriptus (Dalla Torre, 1890) é descrito pela primeira vez e são dadas novas ocorrências de Bothranthidium lauroi Moure, 1947, no Peru.

Palavras-chave. Dianthidiini; espécies novas; novos registros; região Neotropical; taxonomia.

Tanto Duckeanthidium Moure \& Hurd, 1960, como Grafanthidium Urban, 1995, são Dianthidiini de porte robusto, sem carena occipital e com a carena pré-episternal curta; os machos têm franja longa e arqueada nos basitarsos anteriores e projeções laterais no sexto tergo; nas fêmeas, as pernas anteriores são revestidas com cerdas eretas com as pontas muito finas e onduladas. O macho de Duckeanthidium é caracterizado por ter o sétimo tergo ornado com três projeções digitiformes longas e o segundo esterno com lobos laterais largos e carenados; a fêmea tem pilosidade mesoscutal densa, mais longa que o diâmetro do ocelo; o macho de Grafanthidium tem o segundo esterno normal, sem projeções lobuladas e dois lobos carenados no sétimo tergo; a fêmea tem pilosidade fina e curta no mesoscuto. Os Anthodioctes Holmberg, 1903 têm carena entre as genas e o occipício, carenas pré-episternais longas e carena dorsal no primeiro tergo, o tegumento densamente pontuado e a pilosidade geralmente pouco conspícua. A descrição do macho de Anthodioctes indescriptus (Dalla Torre, 1890) é apresentada pela primeira vez.

O material-tipo das espécies estudadas está depositado no Museu de História Natural "Javier Prado", Universidad Nacional Mayor de San Marcos, Lima (MUSM) e na Coleção de Entomologia "Pe. J. S. Moure", Departamento de Zoologia, Universidade Federal do Paraná, Curitiba (DZUP).

\section{Duckeanthidium tarapotoense sp. nov.} (Figs. 1 - 3)

Diagnose. Macho com faixa subapical amarelo-pálida no clípeo, quase toda a face externa das mandíbulas e nódoas nos tergos também amarelo-pálidas; pilosidade predominante enegrecida inclusive nos basitarsos anteriores. Fêmea sem desenhos amarelos na cabeça, com máculas amarelo-pálidas lembrando setas nos lados dos tergos, escopa preta com área esbranquiçada nos esternos basais.

Holótipo macho. Comprimento aproximado 14,5 mm; comprimento da asa anterior a partir do esclerito costal 12,4 $\mathrm{mm}$; largura da cabeça $4,7 \mathrm{~mm}$. Tegumento preto, menos as seguintes áreas amarelo-pálidas: mancha discal quase retangular nas mandíbulas, faixa subapical no clípeo, mais larga nos lados e nódoa em forma de gota na ponta do escapo; primeiro e quinto tergos com duas pequenas manchas laterais pouco visíveis dorsalmente, o segundo com manchas laterais elipsoides, terceiro e quarto tergos com duas máculas médiodorsais e duas laterais. Primeiro flagelômero com área basal ferrugínea. Mesosoma e pernas pretos, as pernas anteriores e medianas com o tarsômero distal castanho; asas tingidas de ferrugíneo, nas anteriores a ponta enegrecida.

Pilosidade da face mesclada de branco e preto, pouco densa nas paroculares e esparsa no clípeo; preta e densa no mesosoma, branca nas áreas ventrais e látero-ventrais dos mesepisternos; pernas com os pêlos pretos predominando, as anteriores com coxa e trocanter castanhos, as medianas e posteriores com pêlos brancos curtos nas coxas; basitarsos anteriores e medianos com franja preta, longa e arqueada na margem externa; na face ventral dos basitarsos anteriores, esbranquiçada, na dos medianos e posteriores, enegrecida com a parte distal castanho-amarelada, nos demais tarsômeros esbranquiçada; preta nos tergos; branca do primeiro ao quarto 
esterno, nos dois distais enegrecida; segundo esterno com cerdas finas e longas um pouco enroladas na ponta; no terceiro e quarto semi-ereta, arqueada para o meio, mais longa que os esternos nos flancos e diminuindo em direção ao meio, deixando área mediana com pêlos finos eretos esparsos; nos distais semi-ereta.

Sexto tergo com depressão rasa triangular entre os lobos laterais, estes dirigidos para trás, mais largos que o espinho mediano do tergo distal e arredondados na ponta; sétimo tergo com lobos laterais longos e levemente divergentes, o espinho mediano curto.

Alótipo fêmea. Comprimento aproximado 13,5 mm; comprimento da asa anterior a partir do esclerito costal 10,1 $\mathrm{mm}$; largura da cabeça $4,7 \mathrm{~mm}$. Cabeça e mesosoma pretos, tergo basal com um par de máculas amarelo-pálidas de contorno irregular nos lados, visíveis dorsalmente; do segundo ao quinto tergo com desenhos amarelo-pálidos laterais peculiares, lembrando setas voltadas para o meio do tergo, expandidas para os lados em forma de faixa muito fina devido ao profundo recorte anterior e alargando nos cantos do segundo e terceiro; tergo distal preto.

Pilosidade preta, inclusive na cabeça, escopa preta, menos no primeiro e lados do segundo esterno, esbranquiçada. Quarto e quinto tergos com pontuação diferenciada nos dois terços basais, os pontos maiores intercalados com pontos pequenos e espaços lisos distintamente maiores que os pontos.

Holótipo macho. PERU, SM [San Martin], Tarapoto-Yurimaguas km 20, IX-X.2002, Rasmussen \& Ríos leg. (MUSM). Alótipo com os mesmos dados (DZUP). Coletados em flores de Vismia Vand. (Hypericaceae).

Comentários. Duckeanthidium megachiliforme (Ducke, 1907) do Pará e Amazonas, é a espécie que mais se assemelha à $D$. tarapotoense sp. nov., porém difere pela margem larga translúcida, amarelo-acastanhada dos tergos; o macho, pela franja longa amarelo-mélea nos basitarsos anteriores e medianos, e a fêmea, pela pontuação densa e uniforme no quarto e quinto tergos, máculas amarelas pequenas e pouco conspícuas nos tergos, o distal castanho.

Etimologia. Nome alusivo à localidade-tipo.

\section{Grafanthidium yurimaguasano sp. nov.}

$$
\text { (Figs. 4, 5) }
$$

Diagnose. Tegumento predominantemente preto; o macho com áreas ferrugíneas nas antenas, pernas e tergos distais; mácula clipeal amarelo-pálida profundamente dividida em três lóbulos alongados, máculas também amarelas nas paroculares inferiores e duas nódoas pequenas no quinto tergo; fêmea sem desenhos amarelos.

Holótipo macho. Comprimento aproximado $8,5 \mathrm{~mm}$; comprimento da asa anterior a partir do esclerito costal $8,3 \mathrm{~mm}$; largura da cabeça $2,8 \mathrm{~mm}$. Tegumento preto exceto as seguintes áreas amarelo-pálidas: mácula no clípeo, profundamente recortada em três lóbulos alongados, reduzindo o tegumento preto a duas áreas triangulares junto ao ramo transversal da sutura epistomal; mácula pequena em forma de gota nas paroculares inferiores, até o nível do ramo transversal da sutura epistomal; mancha amarela grande na face externa das mandíbulas, com o contorno arredondado em direção ao ápice e reto junto à área malar. Escapo amarelo-pálido na face ventral, pedicelo preto, o flagelo ferrugíneo na face ventral e enegrecido na dorsal, porém o segundo flagelômero com um pouco de ferrugíneo. Basitarsos enegrecidos, demais tarsômeros ferrugíneo-enegrecidos; asas tingidas de castanho-enegrecido; quinto tergo com duas nódoas amarelas, aproximadamente do tamanho dos ocelos, separadas por distância maior que o escapo; terço distal do sexto tergo e todo o sétimo ferrugíneos; esternos com áreas enegrecidas e ferrugíneas.

Pilosidade branca na cabeça porém castanha no vértice; castanha, alongada e esparsa no mesoscuto e escutelo; nos tergos creme e esparsa, entremeada com cerdas finas alongadas; no tergo distal amarelo-mélea na margem e junto ao recorte mediano dos lobos laterais, os pêlos curtos e voltados para o meio; nos flancos dos esternos amarelo-creme formando tufos ralos, muito curta no disco. Basitarsos anteriores com a franja da margem externa castanha na base e mélea no restante, ultrapassando um pouco a sua largura, os pêlos com as pontas enroladas, os basitarsos medianos sem franja na margem externa.

Escutelo quase sem pêlos, com projeção mediana pequena em forma de "W"; base do propódeo pontilhada e com trabéculas longas, não chegando a formar alvéolos. Sexto tergo com placa subapical voltada para cima, quase perpendicular ao tergo e muito estreita no meio, alargada e arredondada nos cantos; sétimo tergo com dois lobos achatados e carenados, separados por recorte reto no fundo e mais largo que os lobos; segundo esterno com carena discal baixa e ondulada.

Alótipo fêmea. Comprimento aproximado $8,1 \mathrm{~mm}$; comprimento da asa anterior a partir do esclerito costal 7,9 mm; largura da cabeça $3,1 \mathrm{~mm}$. Tegumento preto exceto as antenas ferrugíneas ventralmente, do terceiro flagelômero ao apical. Pilosidade enegrecida exceto nas paroculares inferiores, branca e pouco densa; na área dorsal dos mesepisternos com mistura de pêlos brancos e enegrecidos e, na ventral, com cerdas brancas muito finas dobradas ou enroladas nas pontas; nos artículos basais das pernas como na parte ventral dos mesepisternos; escopa creme.

Holótipo macho. PERU, SM [San Martin], Tarapoto-Yurimaguas, km 20, 14.X.2002; Rasmussen \& Ríos leg. (MUSM). Com a mesma procedência, alótipo (DZUP) e um parátipo fêmea (MUSM).

Comentários. O macho de Grafanthidium paraense Urban, 1995, é o que mais se aproxima do de G. yurimaguasano sp. nov., porém difere por ter a cabeça quase inteiramente preta, somente o clípeo ornado subapicalmente com faixa amarela, escapo enegrecido, sexto tergo com os lobos laterais alongados, maiores que dois diâmetros do ocelo, projetados para trás e o sétimo tergo com os lobos laterais divergentes, separados por recorte circular e quase retos na ponta. A fêmea de G. paraense 

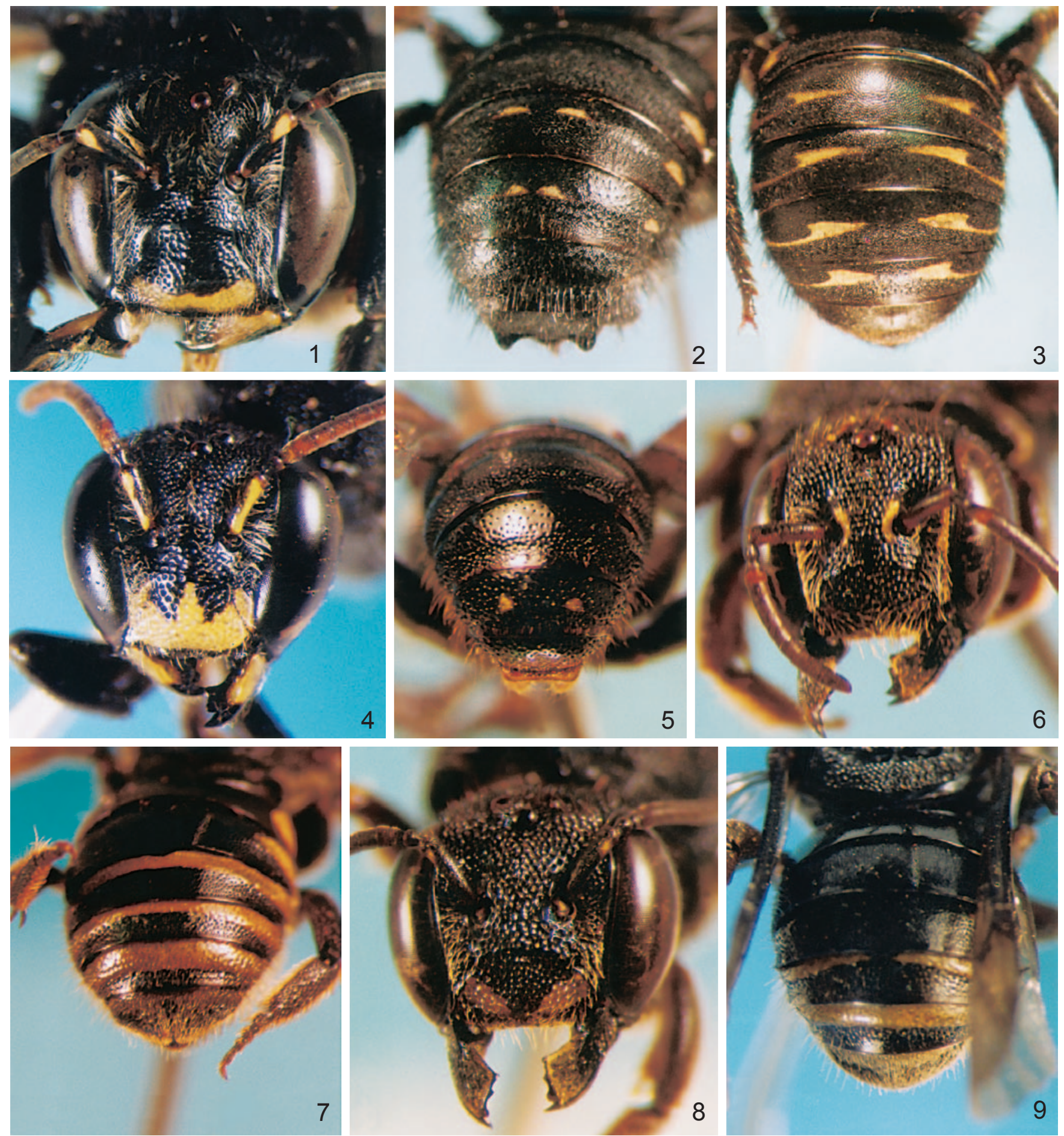

Figs. 1-9. Figs. 1-3, Duckeanthidium tarapotoense sp. nov.: 1, cabeça; 2, tergos do holótipo macho; 3, tergos da fêmea. Figs. 4-5, Grafanthidium yurimaguasano sp. nov.: 4, cabeça; 5, tergos do holótipo macho. Figs. 6-7, Anthodioctes shilcayensis sp. nov.: 6, cabeça; 7, tergos do holótipo fêmea. Figs. 8-9, Anthodioctes sanmartinensis sp. nov.: 8, cabeça; 9, tergos do holótipo fêmea.

não foi descrita. URBAN (1995) deu a conhecer mais duas espécies desse gênero, do norte do Brasil, G. amazonense e G. rondonicola, com máculas amarelas no mesoscuto, escutelo e axilas.

Etimologia. Nome alusivo à localidade-tipo.

\section{Anthodioctes shilcayensis sp. nov.}

(Figs. 6, 7)

Diagnose. Fêmea com máculas amarelas na cabeça, escutelo preto, faixas amarelas do terceiro tergo ao distal, tergo basal 
com pontos finos também dos lados e com áreas látero-basais lisas. Macho com carena genal justaorbital longa e irregular, sem área lisa porteriormente; escutelo e axilas, em parte, amarelos.

Holótipo fêmea. Comprimento aproximado $8,0 \mathrm{~mm}$; comprimento da asa anterior a partir do esclerito costal $6,0 \mathrm{~mm}$; largura da cabeça $2,7 \mathrm{~mm}$. Tegumento preto com as seguintes áreas amarelas na cabeça: nódoas pequenas subapicais nos lados do clípeo, estria parocular muito fina junto aos olhos, até pouco acima dos alvéolos, alargando-se um pouco na altura da tangente alveolar inferior; estrias em arco junto aos alvéolos, divergentes dorsalmente; mácula alongada na metade dorsal das genas. Mesosoma sem manchas amarelas; asas tingidas de castanho-enegrecido. Primeiro e segundo tergos com máculas laterais amarelas, pouco visíveis dorsalmente, arredondadas no primeiro e ovaladas no segundo; do terceiro tergo ao distal com faixa amarela ocupando o disco e parte da área basal, com o bordo largamente preto, no sexto tergo a área amarela com contorno bissinuoso.

Pilosidade inconspícua, no mesoscuto e escutelo castanha e curtíssima, nas pernas creme-acastanhada; do terceiro ao quinto tergo um pouco mais longa, esparsa e mais ou menos ereta; escopa esbranquiçada.

Clípeo sem carena mediana, supraclipeal com área mediana lisa, curta e sem pontos; genas, de perfil, quase tão largas quanto os olhos e com os pontos grandes como os dos mesepisternos, com carena justaorbital quase até o meio; mesoscuto com a pontuação chegando às carenas laterais; tergo basal com faixa marginal lisa um pouco mais estreita que o diâmetro do ocelo, com pontos finos muito esparsos junto à carena transversal, deixando áreas lisas maiores que o diâmetro do ocelo, no disco a pontuação mais densa, os pontos separados por espaços iguais a duas ou três vezes seu tamanho, rasos e maiores nos flancos; no segundo e terceiro tergos a margem lisa mais estreita do que no primeiro, com os pontos finos como na parte discal do primeiro; no quarto e quinto com pontos um pouco maiores e mais densos.

Alótipo macho. Comprimento aproximado $6,4 \mathrm{~mm}$; comprimento da asa anterior a partir do esclerito costal $5,2 \mathrm{~mm}$; largura da cabeça 2,4 mm. Tegumento preto, menos as seguintes áreas amarelas: mácula grande na metade basal das mandíbulas, a ponta castanha; o clípeo, exceto a margem e duas manchinhas triangulares junto ao ramo transversal da sutura epistomal, castanhos; mácula nas paroculares inferiores, contornando a sutura subantenal e diminuindo em direção às órbitas, terminando dorsalmente aos alvéolos; nódoa amarela vestigial junto ao alvéolo esquerdo, no lado direito o tegumento preto; genas com pequena mancha junto às mandíbulas e estria na metade dorsal. Antenas com o escapo inteiramente amarelo na face ventral, primeiro flagelômero amarelo-ferrugíneo. Metade distal do escutelo e disco das axilas amarelos; tégulas castanhas; asas tingidas de castanho; pernas com os artículos basais castanho-escuros, face posterior dos fêmures anterio- res e medianos castanha, os fêmures posteriores inteiramente castanhos, demais áreas dos fêmures anteriores e medianos amarelo-âmbar com faixa amarela na face ventral, ao longo do comprimento; tíbias amarelo-méleas com longa estria castanha na face externa, nas anteriores e medianas a estria precedida de área amarela alongada; tíbias posteriores com amarelo no ápice da face externa; basitarsos com a face externa amarela, demais tarsômeros castanho-amarelados. Dois tergos basais com máculas laterais amarelas, pouco visíveis dorsalmente, ovaladas no primeiro e formando pequenas faixas laterais no segundo; do terceiro ao quinto com faixa discal amarela, estreita no terceiro e mais larga nos seguintes; nos tergos distais predomina o amarelo; a faixa marginal do primeiro ao terceiro tergo castanha e nos demais amarelada e translúcida. Esternos castanhos com faixas amarelo-ferrugíneas finas e irregulares.

Pilosidade do mesoscuto e escutelo castanha, ereta e esparsa, mais longa que a metade do diâmetro do ocelo; do terceiro ao quinto tergo ereta, castanha e esparsa; esporões tibiais posteriores curtos, normais.

Clípeo e supraclipeal sem carena ou área lisa mediana; genas, de perfil, mais estreitas que os olhos, carena justaorbital longa e irregular, quase até o vértice e sem área lisa posteriormente; tergo basal com áreas laterais desprovidas de pontos, junto à carena transversal, faixa marginal lisa e larga; nos demais tergos a faixa marginal lisa mais estreita que a do primeiro; pontuação fina e densa do primeiro ao terceiro tergo porém mais densa no segundo, no quarto e quinto os pontos maiores e mais densos.

Holótipo fêmea. PERU, SM [San Martin], Tarapoto, Boca Toma (Shilcayo) 400-900m, 31.VII.2002, Claus Rasmussen leg. (MUSM). Alótipo e um parátipo macho com os mesmos dados do holótipo (DZUP); um parátipo macho de Tarapoto, Yurimaguas km 20, IX-X.2002, Rasmussen \& Rios leg. (MUSM).

Comentários. O parátipo macho, com os mesmos dados do alótipo, com estrias interalveolares amarelas um pouco divergentes dorsalmente, genas com a mácula amarela ventral quase tão longa quanto o escapo e a dorsal também longa; o outro parátipo macho com as axilas inteiramente pretas. Na chave proposta por Urban (1999) a fêmea sai com A. holmbergi (Cockerell, 1927) da Bolívia e centro-oeste do Brasil, e A. santosi, do sudeste do Brasil. A. holmbergi difere na pilosidade fulva densa nos tergos distais e na pontuação dos tergos, no primeiro os pontos grandes junto à carena transversal porém pequenos e densos no restante do primeiro tergo e nos seguintes. $A$. santosi, como $A$. shilcayensis $\mathbf{s p . ~ n o v . , ~ n a ̃ o ~ t e m ~ c a r e n a ~ n o ~ c l i ́ p e o ~}$ e a pilosidade do terceiro ao quinto tergo é pouco conspícua; contudo, difere pelo terceiro tergo, com a faixa discal amarela fragmentada, pela faixa marginal larga e translúcida amareloâmbar no quarto e quinto tergos e pelo tergo distal inteiramente amarelo. O macho de $A$. shilcayensis segue até o dilema 22 da mesma chave, junto com A. lunatus (Smith, 1854), do norte do Brasil, que tem escutelo e axilas inteiramente amareloalaranjados, área interalveolar preta e não tem manchas amarelas nas pernas.

Etimologia. Nome referente à localidade-tipo. 


\section{Anthodioctes sanmartinensis sp. nov.}

(Figs. 8, 9)

Diagnose. Fêmea com máculas amarelas no clípeo, escutelo preto e os dois tergos basais pretos, o terceiro com estrias laterais amarelas pequenas, quarto tergo com faixas amarelas laterais quase até o meio e faixa marginal preta larga, um pouco angulosa, quinto e sexto com faixa amarela discal larga e faixa preta apical também larga; tergo basal com áreas lisas láterobasais. Macho com carena justaorbital longa nas genas e área lisa posterior à mesma, escutelo preto; pernas com áreas amarelas, castanhas e enegrecidas e os dois tergos basais sem faixa amarela completa.

Holótipo fêmea. Comprimento aproximado $8,4 \mathrm{~mm}$; comprimento da asa anterior a partir do esclerito costal $6,8 \mathrm{~mm}$; largura da cabeça $2,9 \mathrm{~mm}$. Tegumento preto menos as máculas látero-apicais amarelas no clípeo e duas nódoas minúsculas ferrugíneas nas paroculares inferiores; antenas castanhoescuras com nódoa apical amarela no escapo; nódoa ferrugínea na área ventral nos lobos pronotais. Tégulas e pernas enegrecidas, asas tingidas de castanho. Tergos basais pretos, o terceiro com estrias amarelas pequenas aos lados, quarto com faixas amarelas laterais estreitas, separadas no dorso por aproximadamente um diâmetro de ocelo e mais afastadas do bordo no meio do que nos lados; os dois tergos distais com faixa discal larga amarela e faixa marginal preta também larga.

Pilosidade castanha na cabeça, dorso do mesosoma e nos três tergos basais, pouco conspícua no mesoscuto e escutelo; esbranquiçada e curta nos demais tergos, com mistura de pêlos longos; pernas anteriores com revestimento cerdoso castanhopálido nos trocanteres, fêmures e face externa das tíbias e dos basitarsos, as medianas e posteriores com a face externa das tíbias e basitarsos também castanho-pálida; escopa em grande parte creme, distalmente acastanhada.

Clípeo sem carena mediana, área supraclipeal com carena fraca formada pelo alargamento das cristas entre os pontos. Genas, de perfil, pouco mais estreitas que os olhos, com pontos menores que os dos mesepisternos e mais rasos, os espaços planos, com carena justaorbital ultrapassando a metade do comprimento das genas e um pouco mais larga que a crista dos pontos; mesoscuto com depressão lisa junto às carenas laterais, ao longo do comprimento. Tergo basal com pontuação fina e rasa, pontos separados por duas a quatro vezes seu diâmetro, com áreas lisas laterais e junto à carena transversal, a margem lisa quase tão larga quanto o diâmetro dos ocelos, látero-ventralmente com pontos tão grandes como os mesepisternais, porém rasos; no segundo e terceiro tergos mais densa que no primeiro, no quarto e quinto tergos os pontos um pouco maiores que nos anteriores e mais esparsos.

Alótipo macho. Comprimento aproximado 7,5 mm; asa danificada; largura da cabeça $2,7 \mathrm{~mm}$. Predomina o tegumento preto. Cabeça com as seguintes áreas amarelas: nódoa basal nas mandíbulas, quase todo o clípeo menos duas nódoas pretas junto ao ramo transversal da sutura epistomal; máculas nas paroculares largas embaixo e estreitando-se angulosamente em direção às órbitas, prolongadas dorsalmente em estria fina até um pouco acima dos alvéolos; nódoas interalveolares arqueadas, curtas e muito próximas aos alvéolos; nódoa amarelo-escura nas genas perto de vértice. Antenas castanhas na face ventral, com mancha amarela alongada na metade apical do escapo, primeiro flagelômero amarelo-ferrugíneo. Tégulas enegrecidas, asas tingidas de castanho. Pernas castanhoenegrecidas, com as seguintes máculas amarelas: estria ventral longa nos fêmures e nódoa alongada na face ventral das tíbias anteriores; nódoa subapical na face ventral dos fêmures medianos e mácula na face externa dos basitarsos posteriores. Dois tergos basais com máculas laterais amarelas, arredondadas no primeiro e ovaladas no segundo; o terceiro com faixa discal amarela ocupando um terço do comprimento do mesmo e faixa marginal preta larga; no quarto tergo a faixa amarela mais larga e a faixa marginal preta mais estreita que a do tergo anterior; demais tergos com o amarelo predominando e a margem finamente enegrecida. Esternos em parte castanhos e em parte enegrecidos.

Pilosidade esbranquiçada na metade ventral da face, castanha na parte dorsal; no mesoscuto e escutelo castanhoamarelada, ereta e esparsa; branca na face ventral do mesosoma e do metasoma; nos tergos esbranquiçada, curtíssima nos basais e, do terceiro ao quinto também curta, porém com mescla de cerdas longas esparsas. Clípeo sem carena, supraclipeal com estria lisa mediana; genas, de perfil, igualando a metade da largura dos olhos, com carena justaorbital longa, quase até o vértice e com larga área lisa posteriormente; mesoscuto com depressão lisa junto às carenas laterais, ao longo do comprimento, como na fêmea. Esporões tibiais posteriores curtos, normais. Tergo basal com espaços látero-basais grandes desprovidos de pontos; do primeiro ao terceiro tergo com pontos finos, pouco menores no segundo, no quarto e quinto esparsos e pouco maiores.

Holótipo fêmea. PERU, SM [San Martin], Tarapoto, Boca Toma (Shilcayo), 400-900m, 31-VII-2002, Claus Rasmusssen leg. (MUSM). Alótipo e um parátipo macho de Tarapoto, Yurimaguas, Km 20, IXX.2002, Rasmussen \& Rios leg. (DZUP).

Comentários. Na chave de Urban (1999) a fêmea desta espécie sai juntamente com A. vernoniae (Schrottky, 1911) conhecida do Paraguai, Argentina e Brasil (Espírito Santo e Paraná). A. vernoniae difere principalmente pelo metasoma com pontos pequenos e densos nos três tergos basais, até o bordo, exceto no tergo basal que tem pontos grandes junto à carena transversal e nos flancos; do quarto ao sexto tergo com pilosidade amarelo-alaranjada densa, os pêlos alargados para a base e o quarto e quinto tergos com faixa marginal translúcida larga amarelo-arruivada. O macho de $A$. sanmartinensis sp. nov., na chave citada acima, sai junto com A. salvatoris Urban, 1999, de El Salvador e A. santosi Urban, 1999, do Brasil (Rio de Janeiro e São Paulo). Estas duas espécies diferem pelas faixas láterobasais amarelas no mesoscuto, carena genal orlada posteriormente por pontos e sem área lisa e pelo mesoscuto com depressão pontuada junto às carenas laterais, ao longo 
do comprimento.

Etimologia. Nome alusivo à Província de San Martin, onde foram obtidos os espécimes.

Anthodioctes indescriptus (Dalla Torre, 1890)

Anthidium indescriptum Dalla Torre, 1890: 139.

Anthodioctes indescriptus; Urban, 1999: 159.

Diagnose. Macho com nódoas amarelas aos lados do clípeo, escutelo amarelo-alaranjado, dois tergos basais pretos, o terceiro com faixas laterais amarelas estreitas e no quarto e quinto tergos com a faixa amarela também muito estreita.

Comprimento aproximado $6,7 \mathrm{~mm}$; comprimento da asa anterior a partir do esclerito costal 5,0 $\mathrm{mm}$; largura da cabeça 2,3 mm. Tegumento preto, exceto as seguintes áreas amarelas na cabeça: mácula de contorno irregular na base das mandíbulas; nódoas subapicais nos lados do clípeo, com o contorno discal convergente para o ápice; estrias paroculares finas sobrepassando a tangente alveolar superior; estrias interalveolares curtas, pouco mais longas que a metade do escapo; estria fragmentada atrás dos olhos e ocelos. Antenas com o escapo amarelo-méleo ventralmente e castanho no restante, pedicelo castanho, flagelômero basal amareloferrugíneo, os demais flagelômeros castanho-escuros. Mesoscuto com estrias laterais amarelas muito finas; escutelo e axilas amarelo-alaranjados; tégulas enegrecidas, as asas tingidas de castanho-escuro; pernas castanhas com áreas enegrecidas, sem desenhos amarelos; coxas e trocanteres medianos e posteriores pretos. Dois tergos basais pretos com a face ventral acastanhada, o terceiro com faixas laterais amarelas finas, separadas dorsalmente por uma distância maior que o escapo; quarto e quinto com faixa discal amarela muito estreita, no sexto a faixa amarela mais larga e a margem enegrecida estreita; tergo distal castanho; esternos castanhos com áreas castanho-amareladas.

Pilosidade do terceiro ao quinto tergo branca e um pouco espatulada; genas com pontos grandes, como os mesepisternais, com carena na metade inferior, formada pelas cristas dos pontos, sem área lisa posterior; esporões tibiais posteriores normais, mais curtos que a metade do comprimento dos basitarsos; pontuação densa nos dois tergos basais, os pontos separados por cristas finas medindo cerca de $1 / 3$ do diâmetro dos pontos.

Comentários. Na chave proposta por URBAN (1999) o ma- cho sai no item 6 juntamente com $A$. chiribogae Urban, 1999, conhecida do Equador, que é caracterizada pelo colorido uniformemente preto do terceiro tergo, pequenas nódoas amarelas no quarto tergo e pelos três tergos distais amarelos com a margem finamente preta.

Distribuição. Espécie conhecida, até o momento, do Brasil (Amazonas) e Peru (Junin, Valle Chanchamayo). Este é o primeiro registro para o Acre (Brasil).

Material examinado. BRASIL. Acre: Rio Branco, 18.V.1997, Silva, S. F. leg., um macho e, da mesma localidade e coletor, 08.IX.1997, um macho (sem a cabeça) (DZUP).

\section{Bothranthidium lauroi Moure, 1947}

Bothranthidium lauroi Moure, 1947: 25.

Espécie conhecida anteriormente do Brasil (Espírito Santo, Minas Gerais, Mato Grosso, Mato Grosso do Sul, São Paulo, Paraná, Santa Catarina), Bolívia (Santa Cruz) e Paraguai (San Estanislau) conforme URBAN (1998). Pela primeira vez foi coletada no Peru, San Martin, Rumizapa e Tarapoto, ao longo do rio Shilcayo, $400 \mathrm{~m}$.

Agradecimentos. A Gerardo Lamas e Claus Rasmussen, do Museo de Historia Natural "Javier Prado", Lima, Peru, pelo envio do material para estudo e doação de exemplares à Coleção "Pe. J. S. Moure", e Albino Morimasa Sakakibara, do Departamento de Zoologia, Universidade Federal do Paraná, pela fotos que ilustram o trabalho.

\section{REFERÊNCIAS}

Dalla Torre, K. W. 1890. Hymenopterologische Notizen. Wiener Entomologische Zeitung 9: 97, 139-141.

Moure, J. S. 1947. Novos agrupamentos genéricos e algumas espécies novas de abelhas sulamericanas. Museu Paranaense Publicações Avulsas 3: 1-37.

Urban, D. 1995. Grafanthidium, gen. n. de Dianthidiini do Brasil e uma espécie nova de Duckeanthidium Moure \& Hurd (Hymenoptera, Megachilidae). Revista Brasileira de Zoologia 12(2): 435-443.

Urban, D. 1998. Notas taxonômicas e espécies novas de Nananthidium Moure e descrição do macho de Bothranthidium Moure (Hymenoptera, Megachilidae). Revista Brasileira de Zoologia 15(3): 621-632.

URBAn, D. 1999. Espécies novas e notas sobre Anthodioctes Holmberg (Hymenoptera, Apoidea, Megachilidae). Revista Brasileira de Zoologia 16(Supl. 1): 135-169. 